\title{
DESAIN MATERIAL SWEEPER UNTUK KENDARAAN PENGHISAB DEBU VULKANIK
}

\author{
Wikan Sakarinto ${ }^{1}$, Andhi Akhmad Ismail ${ }^{2}$, Andi Pratama ${ }^{3}$, Putri Chairany ${ }^{4}$ \\ 1,2,3,4 Departemen Teknik Mesin, Sekolah Vokasi UGM, Indonesia \\ Email: wikan_vespa@yahoo.com ${ }^{1}$; andhi_akhmad@ugm.ac.id ${ }^{2}$; \\ andipra007@gmail.com ${ }^{3}$; putri.chairany@gmail.com ${ }^{4}$
}

\begin{abstract}
In overseas, the road sweeper have been producted. But, the expensive of import tax will be fundamental problem for realisation the road sweeper from the overseas. The goal of this observation is making the the road sweeper which will be raised the amout in the future according UGM needed. And the part of the road sweeper is the sweeper itself. The problem which has been observated is giving the proper testing for steel wire as the based material in making a sweeper. Because of that, for knowing the proper testing in the steel wire, then doing observation which has given a different treatment. As the component which has the work with lots of friction, so the sweeper must have high hardness, high wear resistance, and high tensile strength. Based on the result of spectrometer analitic report which was did in science and accelerator technology laboratory-BATAN. Based on the result picture of micro sweeper structur observation with material stainless steel in litterature has a similarity with the picture of austenite and ferrite micro structure which has several overages, especially in strength and high resistance to intergranular corrosion.
\end{abstract}

Keywords: sweeper, microstructure test, stainless steel, road sweeper vehicle

\section{PENDAHULUAN}

Kebersihan lingkungan menjadi hal yang sangat diperlukan karena kesadaran penduduk akan kebersihan semakin meningkat, sejalan dengan tujuan UGM menjadi universitas swakelola sampah. Dengan produksi sampah yang dihasilkan diharapkan dapat segera ditingkatkan kecepatan pembersihan agar tidak mengotori dan mengganggu lingkungan. Bila melakukan pembersihan dengan menggunakan sapu akan menerbangkan debu ke udara, sehingga keefektifan tidak tercapai, sementara membutuhkan banyak pekerja pembersih juga waktu yang diperlukan relatif lebih lama. Maka sistem kebersihan yang cepat dan dapat ditingkatkan derajat kebersihannya sangat diperlukan. Dengan adanya kendaraan penyapu sampah ini maka diharapkan kebutuhan kebersihan lingkungan dapat dicapai secepat-cepatnya dan sebersih-bersihnya tanpa harus menyisakan debu yang berterbangan mengganggu lingkungan.

Di luar negeri, kendaraan penghisap debu dan sampah memang sudah diproduksi. Namun tingginya biaya impor akan menjadi masalah yang fundamental untuk merealisasikan kendaraan penghisap debu dan sampah dari luar negeri. Dan dari ide kendaraan penghisap 
debu vulkanik yang telah dikembangkan oleh UGM, kedepan akan dilakukan pengembangan Kendaraan Penyapu Sampah diharapkan dapat mengatasi masalah dalam menyapu dan menyedot sampah terutama sampah sapuan jalan. Penelitian ini bertujuan untuk membuat kendaraan penyapu sampah yang kedepannya akan diperbanyak jumlahnya sesuai dengan kebutuhan UGM. Adapun bagian dari kendaraan penyapu sampah itu sendiri adalah sweeper (penyapu).

Sweeper merupakan salah satu alat penyapu yang digunakan untuk menyapu sampahsampah yang berada dijalan, seperti daun, plastik, debu, dll. Beban kerja sweeper biasanya adalah beban gesekan. Gesekan tersebut didapatkan saat sweeper bekerja, dan bergesekan dengan material padat yang disapu oleh sweeper itu sendiri. Maka dari itu bagian ini harus memiliki daya tahan gesek yang baik agar sweeper tersebut dapat bertahan lama dalam bekerja. Sifat mekanik yang baik dapat menjadikan sweeper memiliki ketahanan aus dan kekerasan yang baik, maka untuk ini dibutuhkan analisa sifat fisik dan sifat mekanik yang terdapat pada sweeper tersebut.

Pada kendaraan penyedot debu dan sampah dibutuhkan mekanisme sweeper yang mampu menyapu semua debu dan sampah yang berada di jalan.

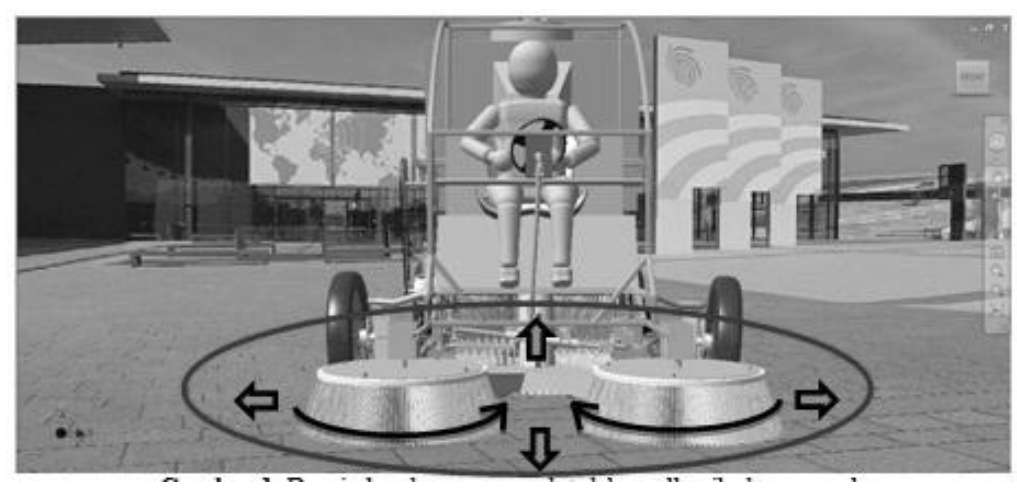

\section{Gambar 1. Desain Kendaraan Penyedot Debu dan Sampah}

Cara kerja dari mekanisme tersebut dapat bergerak ke kanan dan kiri untuk menjangkau debu dan sampah yang lebih jauh, dan naik turun untuk kondisi tidak bekerja dan bekerja, dapat dilihat pada Gambar 1. Berikut adalah desain mekanisme sweeper yang telah dirancang, 


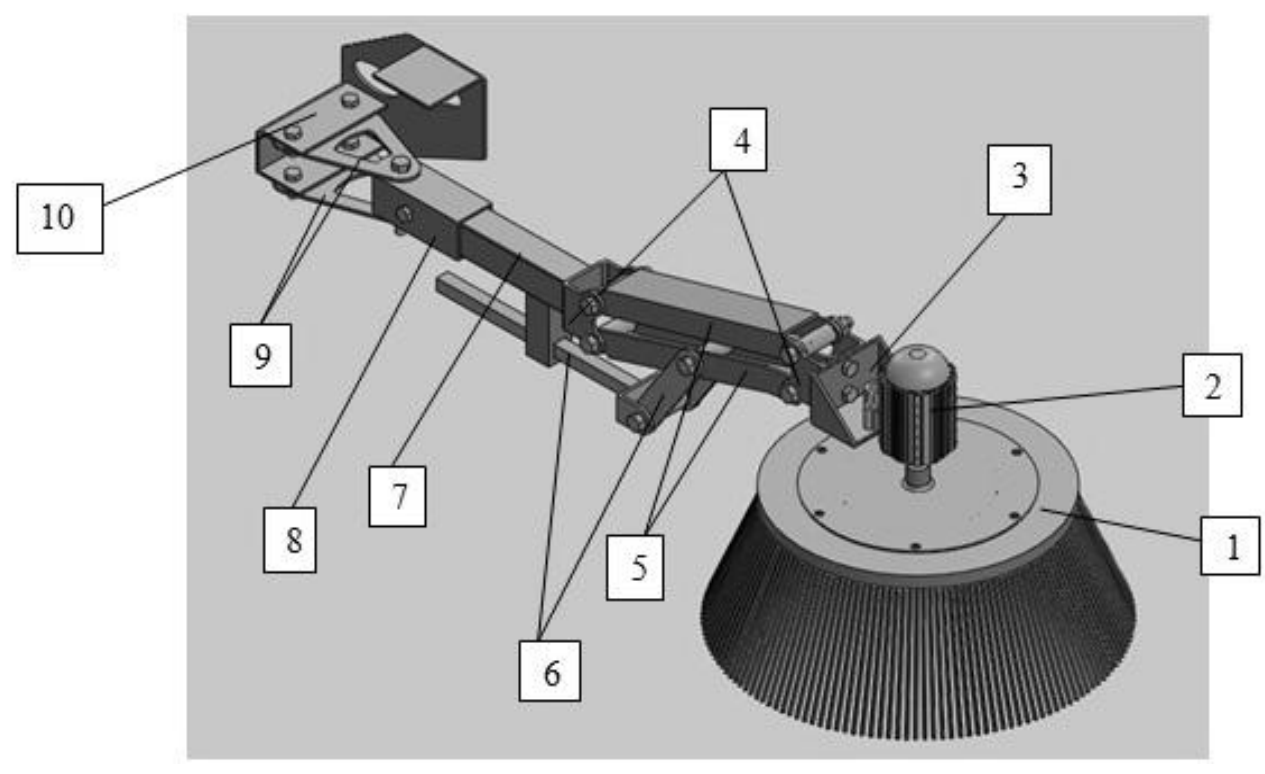

Gambar 2. Desain Mekanisme Sweeper

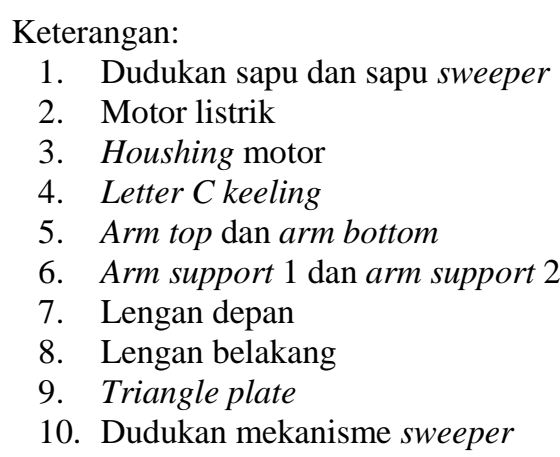

Dari gambar 2 terdapat dua sistem gerak yang terdapat pada mekanisme sweeper, yaitu:

\section{Arm support}

Dapat dilihat pada Gambar 3 untuk bagian mekanisme ini adalah bagian utama dari sistem kerja mekanisme sweeper, yaitu arm support. Cara kerja dari arm support sendiri adalah menaikturunkan arm yang terhubung dengan motor listrik dan sapu, dimana naik atau arm support maju adalah pada saat sapu tidak bekerja dan turun atau arm support mundur adalah pada saat sapu bekerja. Gerak dari arm support dibantu menggunakan motor listrik yang nantinya dipasang pada bagian bawah lengan depan, karena ini projek bertahap jadi desain belum dibuat atau dilanjutkan peneliti berikutnya. 


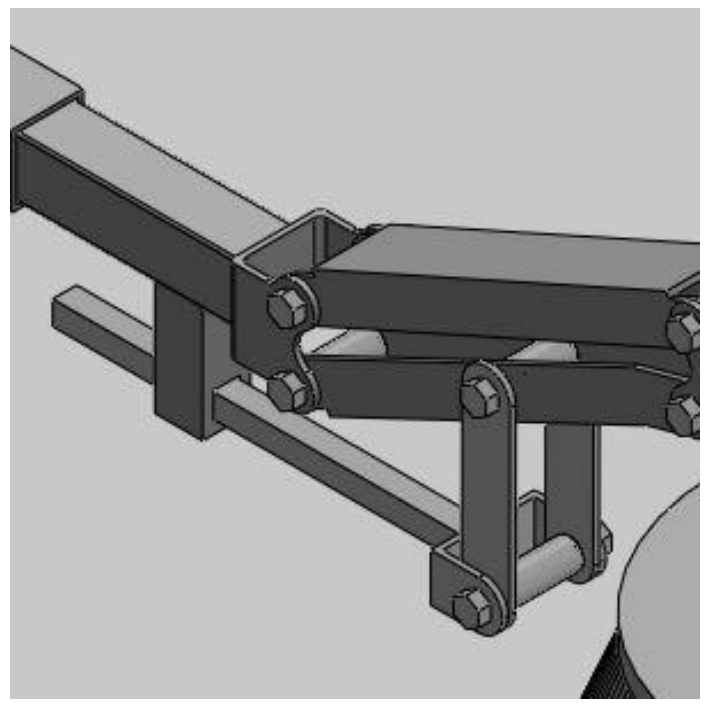

Gambar 3. Mekanisme Arm Support

\section{Lengan sweeper support}

Dapat dilihat pada Gambar 4 untuk bagian ini adalah inti dari seluruh mekanisme sweeper karena semua beban yang ada ditanggung pada mekanisme ini. Cara kerja dari mekanisme lengan sweeper support sendiri adalah menggerakan seluruh bagian sweeper ke kanan ataupun ke kiri untuk menjangkau debu dan sampah yang berada disekitarnya.

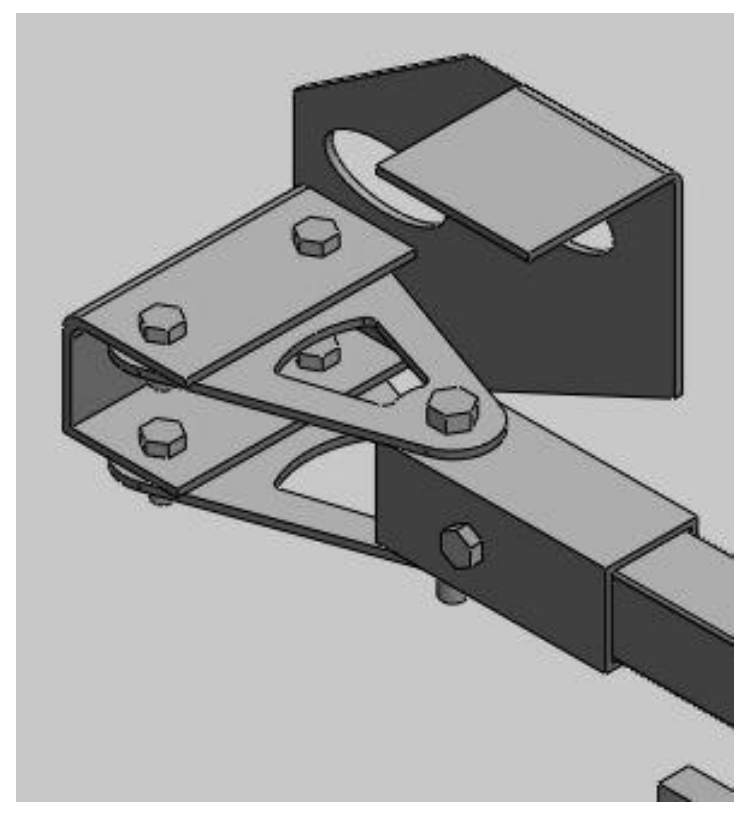

Gambar 4. Mekanisme Lengan Sweeper Support

Berat mekanisme sweeper kurang lebih $35 \mathrm{~kg}$ dan perancangan mekanisme sweeper dibuat beda dari perancangan sebelumnya yang sudah ada, karena perbedaan sistem gerak yang diterapkan menggunakan motor untuk membandingkan dengan yang menggunakan 
hidrolik pada saat performa penyapuan mekanisme sweeper dalam menangani debu dan sampah yang memiliki karakteristik berbeda-beda, yang kemudian dikumpulkan ke vacuum untuk ditangani lebih lanjut.

Berdasarkan latar belakang tersebut dapat ditarik suatu rumusan masalah bahwa kebutuhan kendaraan penyapu sampah yang berupa sweeper berkualitas sangat dibutuhkan. Maka perumusan masalah yang akan diteliti adalah pemberian pengujian yang tepat untuk kawat baja sebagai bahan dasar pembuatan sweeper. Oleh karena itu untuk mengetahui pengujian yang tepat pada kawat baja untuk sweeper tersebut, maka dilakukan penelitian yang telah diberi perlakuan yang berbeda-beda.

Tujuannya untuk mengetahui nilai kekerasan, ketahanan aus, ketahanan tarik, uji komposisi dan struktur mikro pada material kawat baja dengan pengujian masing-masing.

Agar pembahasan lebih terfokus, maka penulis batasi permasalahan menjadi beberapa hal, yaitu material yang digunakan untuk penelitian adalah kawat baja untuk penyapu jalan pada kendaraan penyapu sampah, dan pengujian yang dilakukan pada tiap spesimen (pengujian komposisi kimia dan pengujian struktur mikro).

Baja tahan karat merupakan kelompok baja paduan tinggi berdasarkan pada sistem $\mathrm{Fe}$ $\mathrm{Cr}$, Fe-Cr-C, dan Fe-Cr-Ni dengan unsur paduan utama 10,5-18\% Krom (Cr). Kadar kromium tersebut merupakan kadar minimum untuk pembentukan permukaan pasif oksida yang dapat mencegah oksidasi dan korosi (Lippold dan Kotecki, 2005).

Baja tahan karat (stainless steel) dapat dikelompokan menjadi lima kelompok. Empat diantaranya didasarkan pada karakteristik struktur kristalografi atau struktur mikro dari paduannya. Yang termasuk dalam kelompok ini yaitu; baja tahan karat martensit (martensitic stainless steel), baja tahan karat ferit (ferritic stainless steel), baja tahan karat austenit (austenitic stainless steel), dan baja tahan karat berfasa ganda (duplex stainless steel). Sedangkan kelompok kelima yaitu pengerasan presipitasi baja tahan karat (precipitation hardening stainless steel) yang dikelompokan berdasarkan tipe perlakuan panas (heat treatment) yang digunakan, daripada struktur mikronya (ASM Handbook of Materials for Medical Devices, 2003).

\section{Martensitic Stainless Steel}

Komposisi martensitic stainless steel pada dasarnya merupakan paduan $\mathrm{Fe}-\mathrm{Cr}-\mathrm{C}$ yang memiliki struktur kristal body-centered-tetragonal. Kandungan kromium dalam martensitic stainless steel mencapai 10,5-18\% Cr dan kadar karbon yang bisa lebih dari 1,2\%. Kandungan kromium dan karbon yang seimbang untuk memastikan struktur martensit. Kadar Cr sebanyak ini merupakan batas terendah untuk ketahanan asam. Oleh karena itu, stainless steel jenis ini 
sukar berkarat di udara, tetapi ketahanan karat dalam suatu larutan juga cukup. Sampai suhu $500^{\circ} \mathrm{C}$, baja ini banyak dipakai karena mempunyai katahanan panas yang baik. Sifat mekanik yang baik dari martensitic stainless steel diperoleh dari hasil pengerasan dan penemperan. Nilai kekerasan martensitic stainless steel (>97HRB) membuat baja cocok digunakan dalam aplikasi kedokteran gigi dan alat operasi. Baja jenis ini juga sering dipakai sebagai material alat pemotong, perkakas, dsb.

\section{Ferritic Stainless Steel}

Ferritic stainless steel pada dasarnya merupakan paduan iron-chromium yang mempunyai struktur kristal body-centered-cubic (BCC). Kandungan $\mathrm{Cr}$ dalam baja tahan karat ini biasanya 11-30\% Cr. Tidak seperti martensitic stainless steel, ferritic stainless steel tidak dapat diperkuat dengan heat treatment. Karena laju pengerasan regangan ferit relatif rendah dan cold working secara signifikan menurunkan keuletan, ferritic stainless steel juga tidak dapat diperkuat dengan cold working. Hal ini menyebabkan baja tahan karat jenis ini jarang digunakan dalam dunia medis.

\section{Austenitic Stainless Steel}

Austenitic stainless steel merupakan kelompok stainless steel terluas dalam hal unsur paduan dan penggunaannya. Sama seperti ferritic stainless steel, baja jenis ini tidak dapat diperkeras dengan heat treatment. Austenitic stainless steel pada dasarnya non-magnetik pada kondisi anealing (menguatkan) dan hanya dapat diperkeras secara cold working. Baja tahan karat jenis ini mempunyai struktur kristal face-centered-cubic (FCC). Biasanya memiliki sifat cryogenic yang baik, kekuatan pada temperatur tinggi yang baik serta ketahanan oksidasi yang baik. Kandungan kromium pada baja jenis ini biasanya $16-26 \% \mathrm{Cr}$, kadar nikel $\leq 35 \%$ Ni serta kadar magnesium $\leq 15 \% \mathrm{Mg}$. Dalam variasi lain juga disebut dengan baja tahan karat delapan belas delapan (Sudira dan Saito, 1992) karena komposisi kromium dan nikel yaitu 18\%Cr$8 \% \mathrm{Ni}$.

\section{Duplex Stainless Steel}

Duplex stainless steel merupakan stainless steel berfasa ganda yaitu terdiri dari fasa austenit dan ferit yang didasarkan pada unsur paduannya yaitu $\mathrm{Fe}-\mathrm{Cr}-\mathrm{Ni}$. Material jenis ini biasanya mengandung porsi fase ferit dan austerit yang sama pada struktur mikronya dan ditandai dengan kadar karbon yang rendah $(<0,03 \%)$ dan penambahan Mo, N, Co. Kandungan kromium dan nikel yaitu $20-30 \% \mathrm{Cr}$ dan $5-8 \%$ Ni. Duplex stainless steel sangat jarang digunakan dalam biomedis tetapi biasanya sering digunakan dalam industri oil and gas, petrokimia serta industri kertas. 


\section{Precipitation Hardenable (PH) Stainless Steel}

Precipitation hardenable $(\mathrm{PH})$ stainless steel merupakan kelas $\mathrm{Cr}-\mathrm{Ni}$ yang dapat dikeraskan dengan aging treatment, serta dapat diklasifikasikan menjadi austenitik (misalnya, A-286), semiaustenit (misalnya, 17-7PH) atau martensit (misalnya, 17-4PH). Klasifikasi ini ditentukan berdasarkan mikrostrukturnya. Untuk semiaustenitic dan martensitic PH steel keduanya biasanya digunakan dalam aplikasi dunia medis.

Secara umum, pengaruh unsur paduan yang terkandung pada stainless steel (Indraswari, 2010) dapat diuraikan sebagai berikut:

\section{1. $\operatorname{Karbon}(\mathrm{C})$}

Karbon merupakan elemen stabilisator austenit yang kuat dan juga pembentuk karbida yang biasanya terjadi pada batas butir. Karbon merupakan elemen yang penting yang terlibat dalam sensitisasi. Kestabilan karbida meningkat dengan cepat seiring bertambahnya kadar karbon (Kou, 1987). Pengaruh kandungan karbon juga dapat meningkatkan hardenability, kekuatan ,dan ketahanan aus, menurunkan keliatan, weldability, dan toughness.

\section{2. $\operatorname{Kromium}(\mathrm{Cr})$}

Kromium biasanya ditambahkan untuk mencegah korosi pada baja. Kehadiran kromium akan meningkatkan kestabilan oksida karena tingginya afinitas terhadap oksigen dibandingkan dengan iron. Tingginya kadar kromium dibutuhkan untuk kestabilan oksida dalam lingkungan yang lebih agresif. Selain meningkatkan ketahanan korosi, kromium juga dapat meningkatkan kekuatan pada suhu tinggi dan ketahanan aus.

3. Molibdenum (Mo)

Penambahan unsur Mo ini dapat memperkuat fasa ferit dan menaikkan kekuatan baja tanpa kehilangan keuletan. Molibdenum juga berfungsi sebagai penyetabil karbida, sehingga dapat mencegah pembentukan grafit pada pemanasan yang lama. Karena itu, penambahan Mo kedalam baja dapat menaikkan keuletan dan ketahanan terhadap mulur (creep) pada suhu tinggi.

\section{Mangan $(\mathrm{Mn})$}

Merupakan suatu elemen penyetabil austenit terutama pada temperatur rendah karena dapat mencegah transformasi martensit. Mangan dapat berinteraksi dengan sulfur membentuk mangan sulfida, dimana morfologi dan komposisi dalam sulfida ini dapat memberikan efek yang baik pada ketahanan korosi (Lippold dan Kotecki, 2005) namun menurunkan weldability. 


\section{Nikel (Ni)}

Nikel mempunyai pengaruh dalam menurunkan suhu kritis dan kecepatan pendinginan kritis, memperbaiki kekuatan tarik, menaikkan ketahanan terhadap korosi, dan menaikkan ketangguhan (toughness) atau ketahanan terhadap beban impact.

6. Silikon $(\mathrm{Si})$

Silikon terdapat pada semua jenis stainless steel dan unsur ini ditambahkan untuk deoksidasi selama pelelehan. Keberadaan silikon di batas butir dapat merusak oksidasi lingkungan. Silikon juga dapat menaikkan hardenability dalam jumlah sedikit, tetapi jika kandungan silikon terlalu banyak akan menurunkan keuletan stainless steel.

Augustine (2015) menjelaskan analisa mikro adalah suatu analisa mengenai struktur bahan melalui pembesaran dengan menggunakan mikroskop khusus metalografi untuk mengetahui sifat dan karakteristik bentuk suatu material logam. Pengujian mikrografi ini bertujuan untuk mengetahui bentuk dan kristal logam berupa struktur mikro yang terbentuk akibat proses perlakuan permukaan spesimen uji, hasil dari pengujian struktur mikro ini digunakan untuk mendukung hasil dari pengujian kekerasan. Untuk melakukan analisa struktur mikro ada beberapa tahap yang harus dilakukan. Beberapa tahap tersebut, yakni:

1. Pemotongan (Cutting)

Proses pemotongan material merupakan suatu proses untuk mendapatkan spesimen uji dengan cara memotong atau menguragi dimensi ukuran material uji menjadi dimensi ukuran yang lebih kecil atau sesuai dengan dimensi yang dibutuhkan untuk pengujian. Pemotongan material uji ini bertujuan untuk mempermudah proses pengamatan struktur mikro pada alat uji scanning. Proses pemotongan material ini dapat dilakukan dengan cara pematahan, penggergajian, pengguntingan dan lain sebagainya.

\section{Pembingkaian (Mounting)}

Proses pembingkaian sering digunakan untuk material uji yang mempunyai dimensi yang lebih kecil. Dalam pemilihan media pembingkaian haruslah sesuai dengan jenis material yang akan digunakan. Pembingkaian haruslah memiliki kekerasan yang cukup dan tahan terhadap distorsi fisik akibat panas yang dihasilkan pada saat proses pengamplasan. Proses pembingkaian ini bertujuaan untuk mempermudah proses pengamplasan dan pemolesan.

3. Pengamplasan (Grinding)

Pengamplasan bertujuan untuk meratakan permukaan spesimen uji setelah proses pemotongan. Proses pengamplasan ini merupakan proses yang sangat penting untuk membuat permukaan spesimen uji benar-benar halus agar dapat dilakukan observasi. Proses pengamplasan dibedakan atas pengampalasan kasar dan pengamplasan sedang. Pengamplasan 
kasar dilakukan sampai permukaan spesimen uji benar-benar rata, sedangkan pengamplasan sedang dilakukan agar permukaan spesimen uji lebih halus. Pada saat proses pengamplasan spesimen uji harus diberikan cairan pendingin untuk menghindar overheating akibat panas yang ditimbulkan dari proses pengamplasan.

4. Pemolesan (Polishing)

Proses pemolesan bertujuan untuk menghasilkan permukaan yang benar-benar rata dan sangat halus permukaannya hingga tampak mengkilap tanpa ada goresan sedikit pun pada spesimen uji. Pemolesan dilakukan dengan menggunakan serat kain dan diolesi larutan autosol metal polish berbentuk pasta.

5. Pengetsaan (Etching)

Etsa dilakukan dalam proses metalografi adalah untuk melihat struktur mikro dari sebuah spesimen dengan menggunakan mikroskop optik. Spesimen yang cocok untuk proses etsa harus mencakup daerah yang dipoles dengan hati-hati, yang bebas dari deformasi plastis karena deformasi plastis akan mengubah struktur mikro dari spesimen tersebut. Proses etsa untuk mendapatkan kontras dapat diklasifikasikan atas proses etsa tidak merusak (non disctructive etching) dan proses etsa merusak (disctructive etching).

Tabel 1. Bahan Etsa

\begin{tabular}{ccc}
\hline No & Material & Bahan Etsa \\
\hline 1 & Logam Baja & $\mathrm{HNO}_{3} 2,5 \%$ \\
2 & Logam Besi Cor & $\mathrm{HNO}_{3} 5 \%$ \\
3 & Logam Tembaga & $\mathrm{HNO}_{3} 65 \%$ \\
4 & Logam Kuningan & $\mathrm{HNO}_{3} 65 \%$ \\
5 & Logam Stainless Steel & Aqua Regia $\left(\mathrm{HNO}_{3}+\mathrm{HCl}\right.$ dengan perbandingan $\left.1: 3\right)$ \\
6 & Logam Aluminium & $\mathrm{NaOH} \mathrm{50 \%}$ \\
\hline
\end{tabular}

Setelah semua proses persiapan dilakukan, maka tahap selanjutnya adalah melakukan pengamatan dengan menggunakan mikroskop logam dengan pembesaran yang ditentukan. Dari hasil mikroskopis akan mendapatkan informasi dan analisa data tentang struktur mikro yang terbentuk pada spesimen uji.

\section{BAHAN DAN METODE PENELITIAN}

Pada penelitian ini, penulis menggunakan spesimen uji pada material sweeper dengan kandungan krom tinggi yang digunakan pada kendaraan penyapu sampah. Selain itu bahanbahan pendukung dalam proses penelitian adalah amplas dengan tingkat kekasaran 300, 600, 800, dan 1000, kain bludru, autosol metal polish, etsa AQUA REGIA (HNO3 + HCl dengan perbandingan 1 : 3). Untuk alat pengujiannya menggunakan tang potong, mesin polish, Hairdryer, pipet, dan Metallurgical microscope Olympus PME3. 
Proses pengambilan sample dilakukan dengan cara memotong sweeper menggunakan tang potong. Sample benda kerja yang diambil sesusai dengan kebutuhan yang akan diuji.

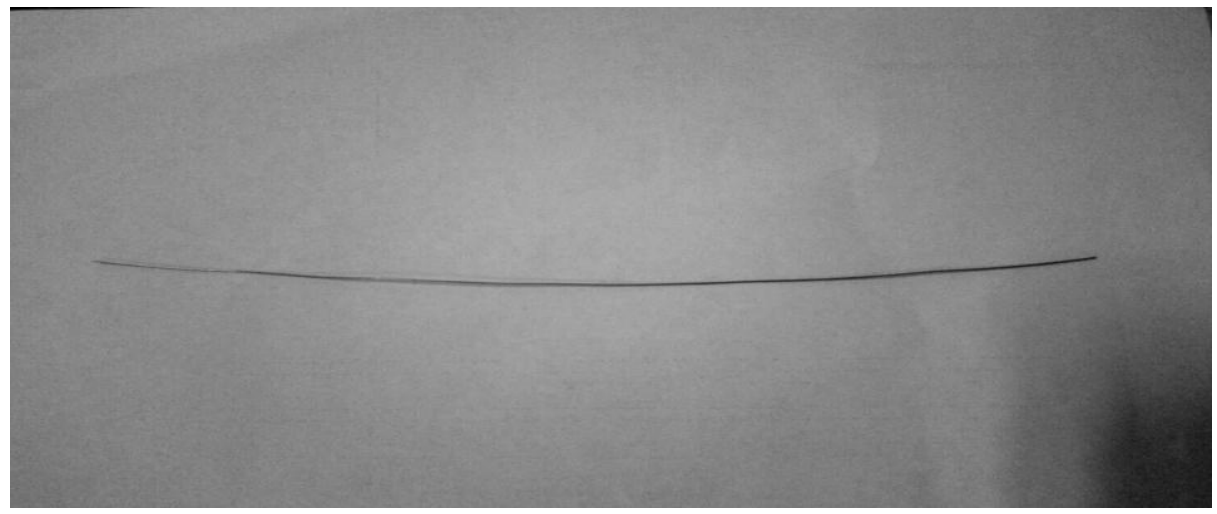

Gambar 5. Spesimen Stainless Steel

Pengujian komposisi kimia dilakukan di Laboratorium Pusat Sains dan Teknologi Akselerator - BATAN. Pengujian komposisi kimia dilakukan menggunakan alat spectrometer dengan tujuan untuk mengetahui kadar komposisi yang terkandung di dalam material Sweeper.

Mounting menggunakan campuran resin dan katalis, dengan perbandingan 10:1. Cetakan yang digunakan dengan bungkus karton atau sejenisnya. Sample benda kerja diletakkan ke dalam cetakan lalu campurkan resin dan katalis dan aduk hingga rata kemudian tuangkan campuran tersebut kedalam cetakan. Mounting bertujuan untuk mempermudah proses pengamplasan dan polish.

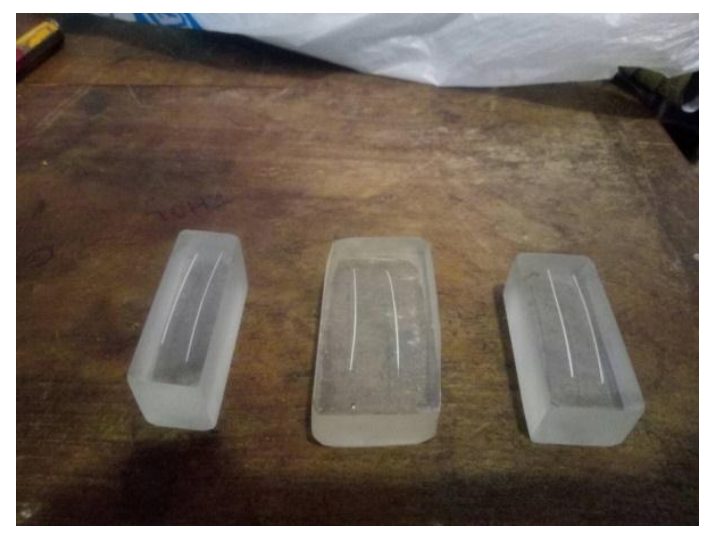

Gambar 6. Hasil Mounting

Proses selanjutnya adalah pengampelasan, dilakukan untuk menghaluskan permukaan material yang akan di uji. Karena untuk mendapatkan hasil struktur mikro yang baik, maka permukaan benda uji harus halus. Pengampelasan dilakukan dengan beberapa tahapan agar didapatkan permukaan benda uji dengan kehalusan yang baik, yaitu pengampelasan dengan kekasaran kertas ampelas 300, 600, 800, dan 1000. 
Pengampelasan dilakukan menggunakan mesin amplas yang berputar, sehingga dalam proses pengampelasan harus selalu didinginkan dengan media air, agar tidak terjadi overheating dan menyebabkan perubahan struktur mikro pada permukaan benda uji. Pada saat melakukan pengampelasan, diusahakan untuk didapatkan permukaan yang rata agar didapatkan gambar yang jelas.

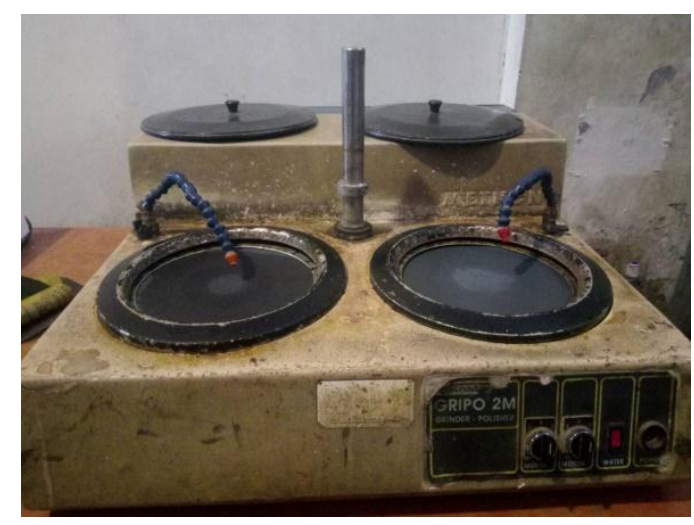

Gambar 7. Mesin Amplas

Selanjutnya pemberian polish dilakukan untuk membuat permukaan benda uji menjadi lebih halus lagi dan agar dapat memantulkan cahaya pada saat dilakukan uji struktur mikro, dan gambar yang dihasilkan pun lebih jelas. Polish ini menggunakan autosol dan kain bludru dengan cara pengerjaan autosol dioleskan pada permukaan speciment lalu gosokan pada kain bludru. Gosok permukaan speciment sampai mengkilap dan benar-benar halus.

Etsa ialah suatu cairan kimia yang berfungsi untuk menampakkan batas butir pada tiap sel struktur mikro pada bahan uji material. Pada kasus kali ini, etsa yang diberikan adalah AQUA REGIA $\left(\mathrm{HNO}_{3}+\mathrm{HCl}\right.$ dengan perbandingan $\left.1: 3\right)$ karena benda yang di uji adalah material stainless steel. Setelah diberi tetesan etsa kemudian permukaan speciment didiamkan selama kurang lebih 4 menit agar batas butir yang dihasilkan maksimal. Setelah itu bersihkan permukaan benda uji menggunakan air dan sabun, dan kemudian dikeringkan dengan hair dryer.

Pengujian struktur mikro bertujuan untuk mengetahui struktur mikro pada sweeper. Pada proses ini menggunakan alat Metallurgical Microscope dengan perbesaran 100X dan 200X. pengujian struktur mikro ini dilakukan di Laboratoium Bahan Teknik Diploma Teknik Mesin Universitas Gadjah Mada. 


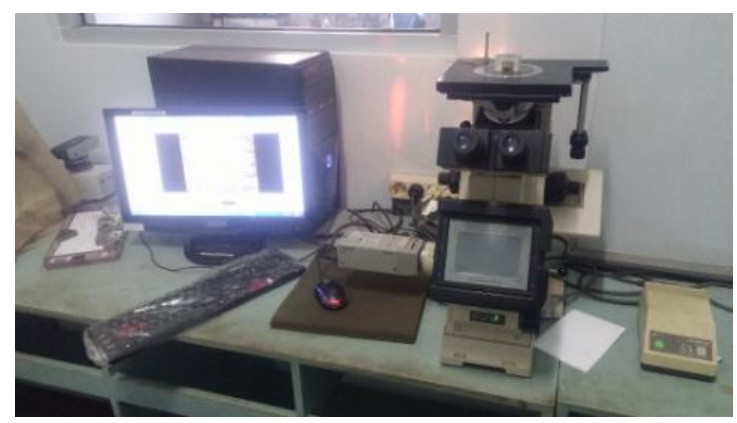

Gambar 8. Metallurgical Microscope

\section{HASIL DAN PEMBAHASAN}

Sebagai komponen yang memiliki kerja dengan banyak gesekan, maka sweeper harus memiliki kekerasan tinggi, ketahanan aus tinggi, dan ketahanan Tarik tinggi. Berdasarkan hasil laporan analisa spectrometer yang dilakukan di Laboratorium Sains dan teknologi Akselerator-BATAN, hasil pengujian komposisi kimia ditunjukkan pada Tabel 2.

Tabel 2. Komposisi Kimia Pada Stainless Steel Untuk Sweeper

\begin{tabular}{ccccc}
\hline No & Unsur & Hasil Uji & Satuan & Metode Uji \\
\hline 1 & $\mathrm{Cr}$ & $23,838 \pm 0,832$ & $\%$ & XRF \\
2 & $\mathrm{Fe}$ & $59,742 \pm 2,913$ & $\%$ & XRF \\
3 & $\mathrm{Ni}$ & $8,093 \pm 0,624$ & $\%$ & XRF \\
\hline
\end{tabular}

Tampak pada Tabel 2 hasil pengujian didapatkan persentase kandungan krom sebesar $23,838 \%$. Ini menunjukkan bahwa spesimen uji merupakan stainless steel, yang memiliki kadar krom diatas $10 \%$. Dari hasil pengujian didapatkan hasil bahwa krom sebagai unsur paduan yang paling dominan sebanyak $23,838 \%$, dan krom tersebut berfungsi sebagai unsur paduan yang akan meningkatkan kualitas sifat mekanik dari material sweeper tersebut. Krom sebagai unsur paduan memilik sifat ketahanan aus yang tinggi dan memperbaiki mampu keras pada suatu material. Sebagai bahan baku sweeper, stainless steel paduan krom tinggi harus memiliki ketahanan aus yang tinggi. Sehingga pemberian kandungan krom yang tinggi sangat tepat untuk material yang proses kerjanya banyak mengalami gesekan.

Penambahan kandungan Ni sebesar 8,093 \% berguna dalam membantu material untuk memperbaiki ketahanan panas dan oksidasi material. Selain itu menurut Clark dan Varney (1952), nikel dengan persentase tertentu dapat meningkatkan ketangguhan, kekerasan permukaan dan kedalaman pengerasan. 
Berikut ini adalah gambar hasil dari struktur mikro:

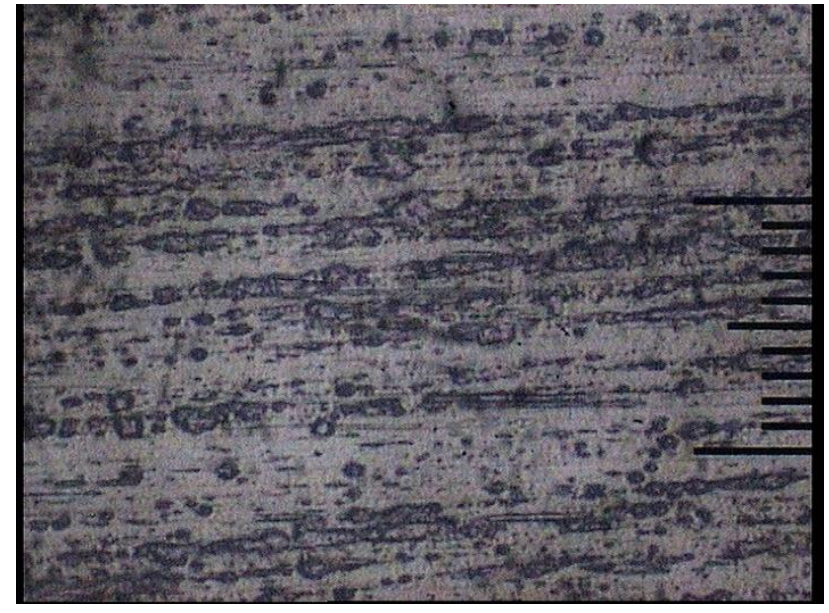

Gambar 9. Hasil Struktur Mikro dengan Perbesaran 200x

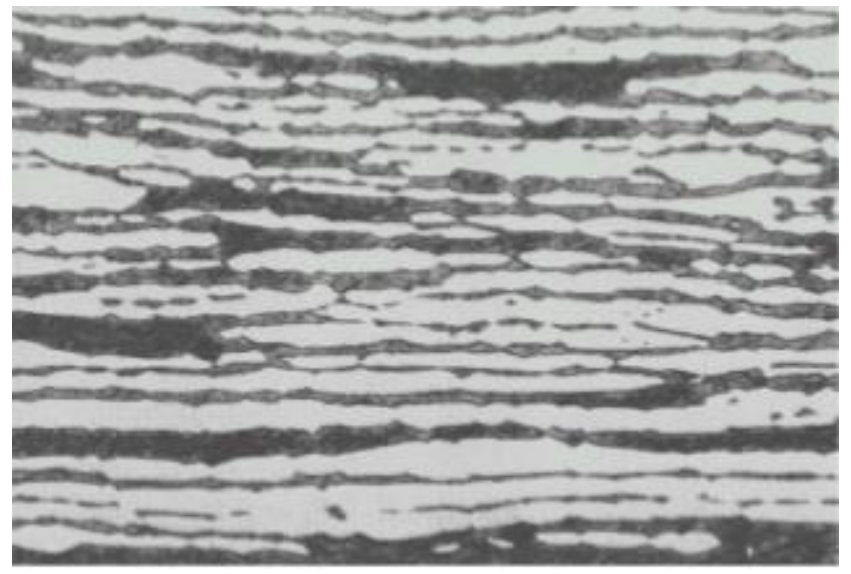

Gambar 10. Structur Micro Duplex Stainless Steel

Berdasarkan gambar hasil pengamatan struktur mikro sweeper dengan material stainless steel memiliki kemiripan dengan gambar struktur mikro duplex stainless steel pada literatur. Duplex stainless steel memiliki dua fasa mikrostruktur austenite dan ferrite yang mana memiliki beberapa kelebihan, terutama kekuatan dan ketahanan yang tinggi terhadap korosi intergranular. Tipe ini mempunyai struktur feritik-austenitik dengan komposisi yang seimbang (50\%-50\%) dan kandungan kromium berkisar 12,5\%-26\%. Untuk bagian yang berwarna hitam menunjukan bahwa itu adalah ferrite yang secara umum fase ini bersifat lunak (soft), ulet ductile), dan magnetic (magnetic) hingga temperatur tertentu. Sedangkan yang berwarna putih menunjukkan austenite yang mana fasa ini bersifat non-magnetic. Sehingga material tersebut mempunyai kekuatan dan ketahanan terhadap korosi yang baik. 


\section{KESIMPULAN}

Berikut merupakan kesimpulan yang dapat disampaikan dari hasil pengujian yang telah dilakukan :

1. Berdasarkan dari uji komposisi kimia dapat diketahui bahwa jenis material yang digunakan pada sweeper adalah stainless steel.

2. Kekuatan tarik pada material sweeper berkisar $2149,68 \mathrm{~N} / \mathrm{mm} 2$.

3. Nilai kekerasan rata-rata sebesar 658,65 VHN. Nilai kekerasan yang cukup tinggi berkemungkinan material tersebut sudah dilakukan proses hardening.

4. Pada hasil penguian analisa struktur mikro didapatkan struktur yang terbentuk adalah ferrite dan austenite. Struktur ferrite dan austenite termasuk dalam jenis duplex stainless steel.

\section{UCAPAN TERIMA KASIH}

Peneliti menyampaikan terima kasih dan penghargaan kepada segenap sivitas PT. YPTI (Yogya Presisi Tehnikama Industri) atas segala bantuan dan dukungan selama proses penelitian ini.

\section{DAFTAR PUSTAKA}

ASM Handbook, Volume 23: Materials for Medical Devices. 2003

Augustine, Fitri Dwi. 2015. Analisa Keausan Material Crusher Batubara. Departemen Teknik Mesin Sekolah Vokasi Universitas Gadjah Mada

Djaprie, Dr. Ir. Sriati. 1991. Dasar Metalurgi Untuk Rekayasawan, PT. Gramedia Pustaka Utama, Jakarta.

Lippold, J.C.and Kotecki, D.J. 2005. Welding Metallurgy and Weldability of Stainless Steels

Seitovirta, Mika. 2013. Handbook of Stainless Steel. Sandvikens Tryckeri. Sweeden.

Sudira T., Saito S. 1992. Pengetahuan Bahan Teknik. Erlangga. Jakarta

Varney, Wilbur R. and Clark, Donald S. 1952. Physical Metallurgy for Engineers 